\title{
Transformaciones y cambios en la policía española durante la II República
}

\author{
José María Miguélez Rueda*
}

\begin{abstract}
RESUMEN
El viejo aparato de Policia que heredó la I/ República se componia de dos colectivos desiguales: el militar Cuerpo de Seguridad, que dependia de los Ministerios de la Gobernación y de la Guerra, era un cuerpo dedicado a prevenir $y$ reprimir las alteraciones del orden público, en cuya labor habia causado y sufrido muchas bajas; por su parte, el menos numeroso y civil Cuerpo de Vigilancia, cuyos miembros actuaban de paisano, debía investigar los delitos $y$ perseguir a los delincuentes, $y$ se

habia distinguido en el reciente pasado por su ejecutoria contra los antimonárquicos. Tras la victoriosa proclamación del 14 de abril de 1931 , gobernantes y policias se observaron con mutua desconfianza y un cierto temor. Los republicanos se propusieron extirpar la desafección, mejorar la eficacia, modernizar los procedimientos $y$ "republicanizar"la
\end{abstract}

\section{ABSTRACT}

The old Police machine that the II Republic inherited was composed by two unequal collectives: the military "Cuerpo de Seguridad" which depended of the Government Office and War Office, it was an institute dedicated to prevent and to repress the public order disorders in which work it had produced and suffered a lot of dead and injured; on the order hand the less numerous and civil "Cuerpo de Vigilancia", whose members worked in plain clothes, had to investigate the crimes and to pursue the criminals, and it had been distinguished its activity against the antimonarchicals in the recent past. After the victorious proclamation of $14^{\text {th }}$ april 1931, the governing persons and the policemen regarded each other with diffidence and a certain fear. The republicans set out to extirpate the disaffection, to improve the efficacy, to modernize the legal procedures and

* Doctorando Historia Contemporánea. UNED. 
fachada y el interior de aquellos "sospechosos" funcionarios. Llevaron

a cabo nuevas realizaciones, modificaron las más y no tuvieron tiempo material de implantar otras propuestas. Los dias 17 y 18 de julio de 1936 sajaron España en dos y arrasaron su obra.

\section{PALABRAS CLAVE}

Policia, Segunda República, Cuerpo de Seguridad, Cuerpo de Vigilancia, orden público. "republicanizar" the fasade and the interior of those "suspicious" public officials. They made effective new realizations, modified most of them and they didn't have enough time to set up another propesals. On the $17^{\text {th }}$ and $18^{\text {th }}$ July 1936 they split up Spain in two halfs and demolished their work.

\section{KEY WORDS}

Police, Spanish Republic, Cuerpo de Seguridad, Cuerpo de Vigilancia, public order.

La Policía española, en cuanto organismo centralizado y dependiente de la autoridad política nacional, fue creada en 1824 por la Real Cédula de 13 de enero y el posterior Reglamento desarrollador de 20 de febrero ${ }^{1}$. Dotada en principio de amplísimas competencias en materia administrativa (formación de padrones, visado de pasaportes, «zelar» sobre las posadas públicas o secretas....) y facultada también para perseguir a todo tipo de delincuentes (desde los "ladrones de los pueblos y los caminos" hasta las asociaciones secretas de “comuneros, masones, carbonarios"...); el desarrollo de la Policía en el siglo XIX transcurrió paralelo y a semejanza de las agitaciones políticas y sociales que vivió nuestra nación ${ }^{2}$.

La Ley de 27 de febrero de 1908 trató de poner fin al marasmo y al estado de obsolescencia en que por entonces se encontraba el organismo de Policía, impotente para atajar las sucesivas embestidas del terrorismo anarquista. Fue una constante en la historia de la institución, es decir, la de crear, con posterioridad al brote del problema, los mecanismos para su erradicación.

Tras este breve preámbulo, veamos cómo era la situación de los cuerpos policiales en los momentos inmediatamente anteriores a la II República y los cambios y reformas acometidos a partir del 14 de abril de 1931.

TuRAado Vidal, Martín, La Policia en la Historia Contemporánea de España (1766-1986). Madrid, Secretaría Técnica del Ministerio de Justicia e Interior, 1995, págs. 87-101

2 Entre las turbulencias ocurridas en el transcurso del siglo XIX cabe citar el recorte de competencias en mayo de 1827, la coexistencia de la Policía Carlista desde abril de 1836 a mayo de 1837, la desarticulación del Cuerpo de Vigilancia y la sustitución por el nuevo Cuerpo de Orden Público en 1868 y las reformas de 1877 y 1886 


\section{EL CUERPO DE INVESTIGACIÓN Y VIGILANCIA ANTES DE LA II REPÚBLICA}

La primera de las dos corporaciones que integraban el aparato policial recibía en 1930 el nombre de "Cuerpo de Vigilancia", y se trataba de un colectivo de carácter civil cuyos miembros vestían de paisano. Sus jefes políticos eran el Ministro de la Gobernación, el Director General de Seguridad (el último con la Monarquía fue Emilio Mola Vidal), y el Gobernador Civil de cada provincia, salvo las excepciones del Campo de Gibraltar - donde dependía del Gobernador Militar-, Mahón —bajo el mando del Delegado del Gobierno-y en las plazas de Soberanía en Marruecos - aquí el Gobernador Civil era sustituido por el Alto Comisario-. El Cuerpo de Vigilancia se estructuraba jerárquicamente en las siguientes categorías profesionales: por un lado, en la base del organigrama, existía una Ilamada "Escala Auxiliar» constituida por los Vigilantes de $1^{a}$ y $2^{\text {a }}$ Clase, los Taquigrafos-Mecanógrafos y los Vigilantes Conductores de 1 ${ }^{a}$, $2^{a}$ y $3^{\text {a }}$ Clase; por otro lado, la "Escala Técnica» se dividía en Agentes de $1^{a}, 2^{a}$ y $3^{a}$ Clase, Inspectores de $1^{a}$ y $2^{a}$ Clase, Comisarios de $1^{a}, 2^{a}$ y $3^{a}$ Clase, Comisarios Jefes, Secretarios Generales y Comisarios Generales. El cargo de Jefe Superior, con carácter mitad político y mitad profesional, oficiaba de mando común a este Cuerpo de Vigilancia y al Cuerpo de Seguridad, que luego veremos ${ }^{3}$.

El ingreso en la Escala Técnica del Cuerpo de Vigilancia se realizaba por el sistema de Oposición (el examen versaba sobre cultura general y conocimientos del sistema legal y político), mientras que en la Escala Auxiliar regía el Concurso, teniendo derecho preferente en este último caso los sargentos y suboficiales del Ejército, así como una reserva del $20 \%$ de las plazas en la Escala Técnica para sargentos de Guardia Civil, Ejército y Carabineros. Después de superar los preceptivos cursos en la Escuela de Policía (dos lectivos a partir de 1925, el primero teórico y el segundo teórico-práctico, con asignaturas de leyes y reglamentos, técnica policial, idiomas, sicología criminal, dibujo y métodos de lucha), el hasta ese momento policía-alumno era nombrado funcionario de carrera con la categoría de Agente de $3^{\mathrm{a}}$ clase. Así comenzaba una vida profesional en la que conocería distintos traslados, varios ascensos por antigüedad y muchas de las plantillas que el Cuerpo tenia desplegadas en todo el territorio español

Así se recoge en el Reglamento de 25 de noviembre de 1930, que fue publicado en la Gaceta de Madrid del día 29 del mismo mes. Sería conocido por el "Reglamento de Mola", al desempeñar éste el puesto de Director General de Seguridad. 
(en general, las Comisarías de Vigilancia se hallaban en las capitales de provincia, núcleos de población más importantes, puestos fronterizos y puertos marítimos de mayor entidad).

Al ser sus reservadas funciones investigar los delitos y faltas tipificados en el Código Penal, hacer cumplir las disposiciones administrativas de policía y controlar las vías de comunicación, puertos, aeropuertos y fronteras, estos policías vestían de paisano y utilizaban un carnet profesional y una placa insignia para identificarse ante los ciudadanos y los detenidos ${ }^{4}$.

El modelo policial respondía a una concepción centralizadora que era reflejo de la organización política de los Borbones, con centro en Madrid, dependencias periféricas en provincias, archipiélagos balear y canario, Marruecos español y Golfo de Guinea. Destacaba por su importancia el foco barcelonés. Los efectivos del Cuerpo de Vigilancia se especializaban en la persecución de los distintos tipos delictivos, agrupándose por esa división del trabajo en Brigadas y Divisiones. Tales eran, en 1930, la División de Investigación Criminal (que se ocupaba de la delincuencia común), la División de Investigación Social (se dedicaba a la persecución de los delitos sociales, las huelgas y las graves alteraciones de orden público), el Servicio de Ferrocarriles, para controlar la delincuencia en las estaciones y los trenes en tránsito, el Servicio de Puertos Marítimos, con idénticas atribuciones en las zonas portuarias, el Servicio de Vigilancia de Fronteras y Extranjeros, a cuyo cargo estaba el control de pasaportes, las entradas y salidas clandestinas del territorio nacional y la supervisión de los extranjeros en España, los Gabinetes de Identificación, dedicados a efectuar la reseña dactilar y fotográfica de los detenidos y a la práctica de las inspecciones oculares técnico-policiales en el lugar del delito, los servicios para la protección de personalidades, las Inspecciones de Guardia, que debian hacerse cargo de los detenidos, efectos incautados y de la recepción de las denuncias, los servicios burocráticos y los servicios de policia administrativa (control de posadas y fondas, establecimientos de juego, garajes y aparcamientos, espectáculos públicos, etc) ${ }^{5}$.

\footnotetext{
José CaAmaño Bournacell señala en su obra inédita La Policia española a través de 50 años (1908 - 1958), págs. 24 y ss. que la placa insignia se estableció por Real Orden de 26 de mayo de 1921, siendo su característica principal la presencia de la corona regia. Un ejemplar de carnet profesional ha sido localizado por el autor en el Archivo Histórico Nacional de Salamanca, Sección Guerra Civil, Serie Politico Social de Madrid, Carpetas 269 y 270.

5 Martín TURRADo, en la página 131 de la obra antes citada, afirma que el origen de estas Brigadas especializadas se sitúa en 1844, cuando se creó el cargo de Comisionado Especial de Vigilancia para "la persecución de los ladrones, vagos, casas de juegos y toda clase de criminales y gentes de mal vivir", por lo que el propio Turrado considera que esta figura era un claro antecedente de la Brigada de Investigación Criminal. Según el autor de este artículo, las razones
} 
¿Cómo eran las interioridades y las condiciones económicas y laborales de los funcionarios del Cuerpo de Vigilancia? El volumen de trabajo al que tenian que hacer frente queda claramente de manifiesto señalando que una plantilla total de casi 3.700 miembros debía cubrir una población de algo más de 20 millones de españoles. Se buscaba paliar esta deficiencia numérica de personal con la realización de unas largas jornadas de oficina y muchas horas de gestiones policiales (vigilancias, seguimientos, atención a confidentes...), lo que ocupaba mañanas, tardes, domingos, festivos e incluso algunas noches, especialmente en los servicios operativos y de investigación. Los sueldos eran escasos en las categorías inferiores, y fue este aspecto una de las mejoras dignificadoras que intentó la II República. El ambiente que se vivía en los últimos tiempos de la monarquía alfonsina fue descrito por Mola en sus memorias. Siguiendo sus páginas, el republicanismo estaba calando en un sector de la Policía, como era el caso de parte de los agentes de Vigilancia en Barcelona. Tras resaltar los pequeños sueldos y las malas condiciones en que prestaban su trabajo, hace hincapié en la apatía e indolencia de muchos profesionales. No obstante, el ataque más fuerte de Mola va dirigido contra los altos mandos de la Policía, que "cuando se logra un éxito policial, aseguran que fue por seguir tal o cual pista, aunque no supieran nada de nada. $Y$ mientras tanto, el verdadero policía, el del soplo a tiempo, el único que no ignoraba ni un solo detalle, andaría por esas calles de Dios, pasando desapercibido, riéndose de unos y de otros [...], de todos". También critica el Director General de Seguridad a los grupos y banderías que se formaban entre los jefes de la Policía, a los que se afiliaban los funcionarios o por buena gana o por necesidad. Le merecian más crédito los humildes funcionarios que la cúpula policial, rodeada de su favoritos, los cuales, a su vez, encumbraban a sus predilectos. Según Mola, la materia prima era buena, pero ganaba poco y se contaminaba del mal ambiente de la superioridad. Aunque no era la regla general, habia muchas tentaciones para el soborno. También alaba encomiásticamente a muchos funcionarios pequeños, modestos en categoría profesional, grandes en honradez, profesionalidad y moral. Respecto a la política de las comisarías, añade que abundaban la recomendación al poderoso y el favor al correligionario ${ }^{6}$.

\footnotetext{
que movieron a los gobernantes del momento para llevar a cabo estas divisiones de la Policía de acuerdo con la tipología delictiva fueron la aparición de una mayor peligrosidad social de los autores de los hechos y la preocupación de los gobiernos por combatir los conflictos sociales o políticos. Por otro lado, en las naciones más desarrolladas del mundo se estaba asistiendo a una división del trabajo policial. Se buscaba con esto, en definitiva, una mayor eficacia y profesionalización de los organismos de Policía.

MOLA VIDAL, Emilio, El Derrumbamiento de la Monarquia. Memorias de mi paso por la Dirección General de Seguridad, Madrid, Editorial Bergua, 1933, págs. 14, 15, 65 y 130.
} 
Finaliza diciendo que la Policía era una colectividad donde reinaban las intrigas, las envidias, los rencores, los odios y las venganzas: "Conocí funcionarios honrados a carta cabal, íntegros hasta la saciedad y laboriosos en extremo, que hubieran podido ser orgullo de cualquier corporación en que los jefes, con juicio imparcial, hubiesen sabido apreciar la labor de sus subordinados" ${ }^{7}$. La vida profesional de estos integrantes del Cuerpo de Vigilancia finalizaba con su jubilación, que estaba fijada en los 62 años para comisarios, inspectores, agentes y personal auxiliar, 60 años para los vigilantes y vigilantes-conductores, y 67 años - aunque eran baja en el escalafón a los 62para los comisarios jefes y secretarios de las Jefaturas Superiores de Policía.

Los trabajos de esa policia de vigilancia abarcaron el campo de la delincuencia común (resolución de los famosos asesinatos de Villaviciosa - Asturias - o del expreso de Andalucía; recuperación de documentos de valor artístico sustraídos en el Museo del Prado y de unas cajas de estimable cualidad artística e histórica que habian sido robadas del domicilio del Marqués de Camarasa; arresto de los autores del robo de joyas y coronas a la Virgen de Covadonga y recuperación de dichos efectos; recuperación de los folios de los libros cantonales de la Catedral de Ávila...) ${ }^{8}$, pero los servicios de mayor resonancia atañeron a la faceta social o política. Una combinación de suerte y paciente investigación fue la clave para llegar al conocimiento de la Sanjuanada de 1926. Según Caamaño Bournacell, uno de los principales conspiradores, cuando se disponía a realizar un viaje en tren y antes de que el convoy partiera de la estación, comprobó la falta de su maletín de viaje, en el que portaba documentos comprometedores relacionados con el inminente movimiento. Tras formular la correspondiente denuncia ante la Policía (parece ser que no esperaba ni remotamente su recuperación) el delincuente común que habia llevado a cabo el hurto fue detenido dos días más tarde a la vez que aprehendido el maletín. Entonces la Policia analizó su contenido, ató cabos y procedió a comunicar el resultado de sus pesquisas a la Direción General de Seguridad ${ }^{9}$.

Por el contrario, entre los fallos más célebres de la Policia española en los primeros 31 años del siglo xx pueden citarse los magnicidios de Dato y Canalejas.

Mola, Emilio, Lo que yo supe. Memorias de mi paso por la Dirección General de Seguridad, Madrid, Bergua, 1933, págs. 17 y ss

Los policias que participaron en las pesquisas y detenciones figuran en las Ordenes Generales del Boletín Oficial de la Dirección General de Seguridad de los dias 29 de febrero de 1924 , 5 de marzo de 1924, 8 de julio de $1924 \ldots$

CaAmañ, ob. cit., págs. 187 y ss. 


\section{EL CUERPO DE SEGURIDAD Y ASALTO ANTES DE LA II REPÚBLICA}

La segunda de las corporaciones que integraban la Policía española recibía en 1930 el nombre de "Cuerpo de Seguridad". Se trataba de un colectivo de naturaleza militar (vestia el uniforme reglamentario en acto de servicio) que dependía del Ministerio de la Gobernación en cuanto a funciones y del de la Guerra en cuanto a mandos, ascensos y categorías profesionales. El Reglamento de 25 de noviembre de 1930 consideraba a este Cuerpo auxiliar del de Vigilancia. Sus jefes políticos eran los mismos que para éste: Ministro de la Gobernación, Director General de Seguridad y Gobernador Civil (salvo las excepciones ya vistas en el apartado I). El Cuerpo de Seguridad se estructuraba en categorías muy similares a las de Guardia Civil y Ejército: 1 Coronel Jefe, Tenientes Coroneles, Comandantes, Capitanes, Tenientes, Suboficiales, Sargentos, Cabos y Guardias. El parecido llegaba hasta el punto de tener unos jefes y oficiales que procedían mayoritariamente de dichos escalafones. Como era un cuerpo de policia independiente, aunque auxiliar del de Vigilancia, disponía de unos centros de trabajo aparte, que se llamaban Acuartelamientos o Cuarteles de Seguridad.

Sus funciones comprendían el mantenimiento del orden público, la seguridad personal, el respeto a las propiedades y la observancia de las leyes. El servicio se organizaba con rondas y patrullas en las ciudades o poblaciones donde se desplegaban sus efectivos. No descuidaban tampoco la instrucción bélica, militar y policial con vistas a prestar sus efectivos como fuerza de choque auxiliando al Ejército o formando grupos de detención en apoyo al Cuerpo de Vigilancia ${ }^{10}$. El punto común con esta corporación era el Jefe Superior, como ya se dijo. En las relaciones normales y cotidianas entre unos y otros, uniformados y de paisano, los mandos de Vigilancia se dirigían a sus homólogos de Seguridad solicitando razonadamente la adscripción temporal de personal de este último para el auxilio en los trabajos de investigación o detención. Era obligatoria la ayuda mutua y recíproca. Para los casos de urgencia todos debian colaborar, y las órdenes emanadas de los funcionarios de Vigilancia habían de ser cumplidas por los suboficiales y sargentos de Seguridad aunque no es-

- Reglamento de 25 de noviembre de 1930 y Gaceta de Madrid de 29 de dicho mes y año. El llamado «Reglamento de Mola" no hizo más que regularizar y ordenar una situación que, en lineas generales, continuaba las directrices dadas por Juan de la Cierva y Peñafiel (Ministro de la Gobernación) en la Ley de 27 de febrero de 1908. Lógicamente. Mola modernizó la regulación legal $y$ el funcionamiento interno de la Policia 
tuvieran presentes los mandos superiores de este Cuerpo. Por supuesto, se produjeron momentos de roce y conflictos.

El Cuerpo de Seguridad contaba con un Servicio de Prevención o de 24 horas de guardia en sus acuartelamientos, que cuidaba del orden, de la seguridad interior y de la custodia de detenidos y efectos depositados; una Sección de Caballería para reprimir a caballo los tumultos callejeros; Servicios de conducción de detenidos; las Secciones de fuerza de Seguridad preparada para intervenir en los casos de alteración del orden público y de la paz ciudadana; los Servicios Locales, que custodiaban los edificios públicos y las Comisarías o Inspecciones de Vigilancia; una Sección de Gimnasia (fue el antecedente próximo de las futuras Secciones de Vanguardia o Asalto); y una Sección especial encargada del servicio de seguridad cerca del Rey y la familia real en los distintos lugares a que acudian y siempre que salian de Palacio ${ }^{11}$.

El uniforme de estos policias de Seguridad era de color gris o azul suave ${ }^{12}$. Los sueldos de los sargentos estaban a la par que los de un agente de $3^{\mathrm{a}}$ clase del Cuerpo de Vigilancia y los de un teniente se acercaban a los del inspector de $2^{\mathrm{a}}$. Por supuesto, las remuneraciones de guardias y cabos alcanzaban una ínfima cuantía.

El ingreso en la categoría de Guardia $2^{\circ}$ se efectuaba por el sistema de oposición tras superar un reconocimiento médico, otro físico y un examen con pruebas de lectura, escritura, aritmética, geometría y preguntas sobre disposiciones legales y reglamentarias. El ascenso de guardia a cabo contemplaba dos posibilidades: el $50 \%$ por antigüedad y el $50 \%$ por oposición. El adiestramiento de los guardias recién ingresados comprendía un período de 3 meses de academia en que se cursaban asignaturas de cultura general, leyes y reglamentos, nociones de urbanidad, práctica policial y esgrima del machete. Una vez superada esta preparación, se fijaba un día a la semana para que, dentro de las unidades donde ya prestaban servicios profesionales, recibieran enseñanzas ampliatorias y de reciclaje, incluyéndose muchas prácticas de tiro con las distintas armas, tanto largas como cortas (carabina y pistola).

Antes de la II República, el Cuerpo de Seguridad utilizaba con gran profusión el sable reglamentario para disolver las manifestaciones y algaradas callejeras. Ello dio lugar a un crecido número de muertos, tanto en

Dicha Sección Especial que protegía al monarca y a la Familia Real tenia como componentes a un suboficial, un sargento, dos cabos y el número de guardias que el primero tuviera a bien disponer.

12 Véase la Real Orden de 29 de julio de 1925 y el Reglamento de 25-11-1930 
las fuerzas actuantes como entre los propios alborotadores. Consciente de la impopularidad y desprestigio que estos sucesos acarreaban a la Policía, Mola se propuso formar un selecto grupo de componentes del Cuerpo de Seguridad que actuarían con una porra de goma revestida de cuero en lugar del mortífero sable. La caída de la monarquía no dio tiempo a llevar a la práctica esta idea novedosa. Por último, decir que los fallecidos por la aplicación de la "Ley de Fugas" supusieron un pesado lastre contra el buen nombre de las fuerzas de orden público, y, en concreto, también lo fueron para el Cuerpo de Seguridad.

\section{LA POLICÍA ESPAÑOLA DURANTE LA II REPÚBLICA}

La Policía Gubernativa no tenía ni el apoyo ni la confianza de los nuevos gobernantes. No en vano, el gobierno provisional recién nombrado había sido perseguido por la Dirección General de Seguridad, y encarcelado posteriormente, tras el fracaso de la sublevación republicana en Jaca y el Pacto de San Sebastían, ambos promovidos por un grupo de políticos tradicionalmente antimonárquicos al que se habían incorporado otros procedentes de los partidos turnantes. Animado este grupo por un programa de profundos cambios, transformaciones y reformas políticas se propusieron levantar el edificio de una nueva Policía más moderna, afecta y eficaz que el aparato heredado de la Monarquía. Cronológicamente, la primera realización práctica afectó al Cuerpo de Seguridad. Miguel Maura (primer ministro de la Gobernación republicano) y Ángel Galarza (su lugarteniente, al mando de la Dirección General de Seguridad) pensaron en la conveniencia de adaptar el antiguo Cuerpo de Seguridad a los nuevos tiempos, y por ello organizaron las llamadas Secciones de Vanguardia o Asalto que, integradas en dicho colectivo, constituirían una fuerza de choque contra las alteraciones del orden público. Así resurgió la idea de utilizar unas fuertes pero no letales porras de goma revestidas de cuero para reprimir de forma incruenta las algaradas callejeras, en lugar del recurso anterior a los disparos y a la bayoneta, que habían causado casi siempre heridos y muertos ${ }^{13}$. Desde el primer momento estas secciones conocieron un gran

\footnotetext{
Normalmente, se considera un "invento" republicano la creación de estas secciones, aunque parece ser que sus origenes se encuentran en la Sección de Gimnasia que ya Mola citaba en sus memorias. Por su parte, Antonio VIQUEIRA HINOJOSA, en la Separata Central de la revista “Policía" de septiembre- octubre de 1993, apuntaba que los comienzos de esta especialización dentro de los componentes del Cuerpo de Seguridad se halla en el domingo 17 de mayo de 1931. Por su parte, Turrado, en la obra citada, página 166, recogía las palabras del propio ministro Maura para concluir que el cuerpo ya estaba perfectamente organizado el día 14 de octubre de 1931 y
} 
desarrollo tanto en medios como en personal. Se puso gran interés en que tuvieran sus miembros una buena preparación física, para lo cual contaban con buenos gimnasios, expertos profesores, excelentes monitores en deportes y atletismo, y ejercicios diarios de instrucción en estas disciplinas (para un guardia de Asalto fueron la gimnasia, la preparación física y el atletismo la base de su preparación y el rasgo elitista que les distinguía de los demás componentes del Cuerpo). Los primeros requisitos que se tenían en cuenta a la hora de ser seleccionados eran la posesión de una buena constitución física (estatura mínima cifrada en 1,70 metros) y una edad joven, de 22 años a 33 como máximo. Su número de integrantes se amplió de una sola vez en 2.500 y las Secciones fueron dotadas con modernos medios de transporte, vehículos de asalto y defensa y tanques que arrojaban agua a presión a los manifestantes. A pesar de la recesión económica que vivía España se asignó un crédito de casi 8.000 .000 de pesetas con destino a la mejora de los medios humanos y materiales. Gobernando ya las derechas republicanas cesaron el Inspector médico, los facultativos del servicio de salud, los profesores de gimnasia y los monitores en preparación física y atletismo. No obstante, al año siguiente se amplió la Sección de Vanguardia o Asalto con el nombramiento de 10 tenientes y de 1.000 guardias, buscando prevenir y combatir en su caso las graves alteraciones del orden público que se esperaban ${ }^{14}$.

Algo posterior en el tiempo fue la creación de la nueva Policia catalana. La base de ésta se encuentra en la serie de disposiciones que, emanadas desde el gobierno de Madrid, convirtieron a Cataluña en la primera comunidad autónoma dentro del Estado Español, dotándola de un gobierno propio y de una policía al servicio de la región. Dada su procedencia "ex-

contaba con 800 hombres que habian demostrado su preparación en diversos servicios policiales Para el autor, el antecedente de los de Asalto se encontraba en la Sección de Gimnasia que Mola menciona en sus memorias (El Derrumbamiento de la Monarquia. Memorias de mi paso por la Dirección General de Seguridad, Madrid, Editorial Bergua, 1933, págs. 65 y ss.), y que era una sección de guardias de Seguridad escogidos por sus condiciones atléticas y que portaban en el desempeño de su trabajo fustas de goma revestidas de cuero.

14 Las Secciones de Vanguardia o Asalto causaron sensación durante la mayor parte del período republicano por la rapidez, eficacia y ausencia de sangre con que solían reprimir las manifestaciones. Respondían a una idea de dureza alejada de los medios letales que diferenciaba a ia II República de los pasados tiempos monárquicos. A pesar de ello se vieron envueltas en los graves sucesos de Casas Viejas. Como se vio más tarde, había también una motivación política en las izquierdas republicanas a la hora de crear las secciones de Asalto, y la labor dio su fruto cuando, iniciada la guerra civil, el Cuerpo de Seguridad y Asalto se incline en mayor medida al bando gubernamental que al franquista. Para comprobar la importancia que le concedieron los gobernantes republicanos, especialmente las izquierdas, ver las Gacetas de Madrid de los días 9 de febrero, 3 de mayo, 24 de agosto y 17 de septiembre (todas ellas de 1932), la del día 8 de octubre de 1933 o la de 22 de marzo de 1934 
novo", se vio precisada a recurrir a miembros voluntarios de los cuerpos policiales ya existentes. Con fecha 2 de abril de 1933 se hicieron públicas las normas para la adaptación del personal del Estado al servicio de la Generalidad. Referida concreta y específicamente a los Cuerpos de Investigación y Vigilancia y de Seguridad y Asalto es la disposición del día 16 de noviembre de 1933, por la que se transferian a la Generalidad de Cataluña las funciones encomendadas hasta ese momento a los cuerpos estatales, facultándose a la Generalidad para organizar libremente los servicios de policía y orden interior en Cataluña. En cuanto a los funcionarios y el personal de ambos cuerpos, podrían optar entre pasar a las plantillas de la región autónoma o continuar en las del Estado ${ }^{15}$. Se reglamentaron las instrucciones para la realización práctica de los servicios, se dispuso que las labores de vigilancia en las líneas ferroviarias extrarregionales continuaria dependiendo de la Dirección General de Seguridad, se previno que la conducción de detenidos seguiria efectuándose en la misma forma y que los gabinetes de identificación conservarían la misma organización. Para el funcionamiento de esta Policía catalana el Gobierno de Madrid habilitó un crédito extraordinario que ascendía a 20.247.861, 20 pesetas. El cuerpo de Policía de Cataluña persistió en su organización hasta la llamada Revolución de Octubre de 1934, cuando la Generalidad se enfrentó con las armas al Gobierno de centro y derechas que mandaba en Madrid. Como consecuencia de esta insurrección contra el gobierno central finalizó el traspaso de los servicios de policía, reintegrándose seguidamente los funcionarios a los escalafones del Estado ${ }^{16}$.

Otra obra nueva que acometió la II República fue la denominada “Oficina de Información y Enlace", adscrita a la Dirección General de Seguridad. La causa de su establecimiento fue la de prestar atención a las tareas y a los servicios de información para la seguridad del Estado, centralizando todos los datos en una oficina que recogía y controlaba cuantos antecedentes tuvieran relación con las noticias «calientes» para los gobiernos

15 Los funcionarios de ambos cuerpos que pasasen al servicio de la Generalidad conservarian los derechos reconocidos en la legislación, no perderían su categoría en los escalatones de procedencia ni la facultad de reintegrarse a los mismos. Incluso podria pedir las plazas de la Generalidad el personal destinado fuera de Cataluña. Con el tiempo los funcionarios de los Cuerpos de Investigación y Vigilancia y de Seguridad y Asalto que pasaron a su instancia al servicio de la Generalidad fueron declarados en la situación de excedencia voluntaria en los escalafones del Estado. Todo ello se regulaba en las Gacetas de Madrid de los días 16.11.1933, 08.05.1934 y 17.07.1934

16 Gacetas de Madrid de los días 27 de noviembre y 12 de diciembre de 1934. Según la revista "Policía" de 2 de abril de 1935 se reintegraron a los escalafones del Estado (procedentes de los de la Generalidad) 689 agentes y 1.984 guardias. 
republicanos en su lucha contra los enemigos interiores y exteriores. Nació la Oficina tras los levantamientos armados de origen anarquista del mes de diciembre de 1932 y 1933 y después de la extendida huelga de campesinos en junio de 1934. En cuanto a su funcionamiento interno, estaba a las órdenes inmediatas del Director General de Seguridad, y el Jefe de la Oficina se nombraba por el procedimiento de libre elección (la actual «libre designación"). El primero de los citados tenía la facultad de destinar a la Oficina al personal de la Policía Gubernativa que estimase conveniente. Se nombró como Jefe de la Oficina al capitán de la Guardia Civil Vicente Santiago Hodson, sustituido en diciembre de 1935 por Alfredo Escobar Huertas. Llegado el Frente Popular fueron sus Jefes el comisario Luis González Molina y más tarde el comandante de la Guardia Civil Francisco Buzón Llanes, quien seguía en su puesto los días 17 y 18 de julio de 1936 , al comienzo de la sublevación ${ }^{17}$.

Otra de las preocupaciones que mostraron los gobiernos de la II República fue la persecución del contrabando y la lucha contra la defraudación. Se tradujo en la creación de la Comisaría General para la represión del contrabando y la defraudación. El nuevo organismo se encuadraba dentro del Ministerio de Hacienda. Básicamente, se centró sobre las rentas de aduanas, los alcoholes, azúcares, achicorias, los cafés, tés y cervezas, así como los artículos y efectos estancados por la Administración, con los del ilícito comercio y con aquéllos cuya importación o exportación se hallaban prohibidas. El organismo llegó a centralizar todos los servicios de policía fiscal. La Comisaría General se constituyó con un Comisario General, un Comisario Jefe, siete Comisarios y un número de Agentes fijados por el Ministerio de Hacienda a propuesta del Comisario General. Los funcionarios adscritos desempeñaban el cometido de la Comisaría General como servicio propio de sus respectivos destinos. Percibían, además de los sueldos correspondientes, las gratificaciones o emolumentos de cualquier clase que tuvieran asignados con anterioridad o les correspondieran por razón de sus cargos en el futuro. El servicio llevaba un libro o Registro General con expresión de los penados por faltas de contrabando y defraudación en el que se consignaban tres apartados: uno para los apodos o alias, otro para la ficha alfabética (nombre, apellidos, domicilio, color del iris, del pelo, marcas corporales, cicatrices y señales identificativas) y el tercer apartado con la reseña dactiloscópica (las "huellas»), caracterizada

La Oficina de Información y Enlace fue creada en la Gaceta de Madrid del día 24.09.1933, siendo Presidente del Consejo de Ministros Alejandro Lerroux y Ministro de la Gobernación Diego Martínez Barrios. A pesar de los trabajos desarrollados para evitar el alzamiento antigubernamental, éste se produjo el 17 de julio de 1936 y pilló desprevenido a gran parte del país. 
por la nota verdaderamente peculiar de carecer del pulgar de ambas manos, pues sólo se practicaba la toma de las impresiones de los dedos índice, medio, anular y meñique (sic) de las manos derecha e izquierda. La zona del Mediterráneo y el contrabando de tabaco por sus costas atrajo la atención de los funcionarios de este organismo, entre los que se encontraban dos hombres del Cuerpo de Investigación y Vigilancia, el comisario Emilio Benzo Ramírez y el agente Gregorio Pérez Huidobro. La Comisaría General procuró el apoyo de las autoridades francesas para combatir eficazmente el desembarco clandestino de tabaco en las costas españolas, llegando a destacarse en Argelia, Orán y París en el curso de las investigaciones. A partir del 1 de julio de 1935 la Comisaria General fue suprimida y sus integrantes se reincorporaron a los puestos de procedencia. Las funciones fueron asumidas desde entonces por los organismos correspondientes del Ministerio de Hacienda, y en especial por el Cuerpo de Carabineros ${ }^{18}$.

Una de las novedades más importantes nacidas durante la II República fue el desarrollo de una Brigada de Policia al servicio del Banco de España (palmaria antecesora de la actual Brigada de Investigación del Banco de España). Comenzó su funcionamiento a finales de 1934 y quedó integrada por 6 miembros del Cuerpo de Investigación y Vigilancia, uno de ellos con la categoría de Inspector. El motivo de su fundación radicaba en la solicitud expresa del propio Banco, que pretendía perseguir los numerosos delitos de falsedad de billetes, de documentos de identidad y de las firmas estampadas en los mismos. Los componentes de la Sección fueron nombrados por el Ministro de la Gobernación a propuesta de la Administración del Banco y tras informe del Director General de Seguridad. Cobraban su sueldo y emolumentos anteriores, a los que había que añadir las gratificaciones y reintegros de gastos que les asignaba el Banco de España. El hecho de que se tratara de una Brigada policial contra la falsedad de billetes y firmas en los documentos del Banco hace pensar que son un lejano antecedente de los actuales grupos de Documentoscopia encuadrados en el área de Policía Científica ${ }^{19}$.

Mejorando ideas pasadas y futuras (entre aquéllas la de 1912), vuelve al panorama español en 1934 la Brigada de Barrios. Sus competencias eran muy variadas (censo de vecinos, de garajes, hoteles y hospederías,

18 La Comisaría General tuvo su génesis en la Gaceta de Madrid del día 29 de mayo de 1934 y fue suprimida un año después, por la Gaceta del día 7 de julio de 1935.

19 La disposición que fundó esta Brigada del Banco de España se encuentra recogida en la Gaceta de Madrid del día 29 de diciembre de 1934. Fue disuelta por la Gaceta de la República de 29 de agosto de 1936 . 
cafés y bares, teatros y cines, pisos alquilados, casas de compraventa, establecimientos de venta al público, registros centrales de electricidad, gas y agua, redes telefónicas, telegráficas y postales, ficheros de calles y casas del barrio, conocimiento de las mudanzas de los vecinos, control de vehículos....). Los integrantes de esta Brigada debían poseer un conocimiento exhaustivo del barrio o distrito que tenían asignado, con vistas a una mejor investigación de los delitos y persecución de los delincuentes. Por tanto, su función primordial era la de colaborar y proporcionar información a las brigadas y grupos operativos del Cuerpo de Investigación y Vigilancia. Una de las fuentes de esa información procedía de las conversaciones con vecinos, comerciantes, empleados públicos y privados, y, sobre todo, de los porteros de los inmuebles ${ }^{20}$.

En cuanto a los retoques o cambios producidos dentro de la Policía, el primer gobierno republicano proyectó un cambio de nombre en el Cuerpo hasta entonces llamado "de Vigilancia". Al mismo tiempo dispuso la actualización de los sueldos y una relativa depuración en sus cuadros. Los dos primeros aspectos fueron recogidos en la Ley de 28 de diciembre de 1932 , en la que, además, se fijaban numéricamente las plantillas de uniformados y de paisano. La Ley, publicada en la Gaceta de Madrid del día 9 de enero de 1933, implantaba la nueva denominación de "Cuerpo de Investigación y Vigilancia", que iba a estar compuesto de 7 Comisarios Generales, 10 Comisarios Jefes, 30 Comisarios de $1^{\text {a }}$ clase, 50 Comisarios de $2^{a}, 70$ Comisarios de $3^{a}, 170$ Inspectores de $1^{\text {a }}$ clase, 250 Inspectores de $2^{\mathrm{a}}$, 820 Agentes de $1^{\mathrm{a}}$ clase, 1.090 Agentes de $2^{\mathrm{a}}$ Clase y 950 Agentes de $3^{a}$, es decir, un total de tres mil cuatrocientos cuarenta y siete miembros de la Escala Técnica del ahora llamado «Cuerpo de Investigación y Vigilancia» ${ }^{21}$. En cuanto al Cuerpo de Seguridad y Asalto, la plantilla fijada era la siguiente: 1 Coronel, Jefe del Cuerpo, 3 Tenientes Coroneles, 14 Comandantes, 81 Capitanes, 231 Tenientes, 91 Suboficiales, 310 Sargentos, 874

20 Iniciada la Guerra Civil, la Brigada de Policia que mandaba Agapito Garcia Atadell (socialista ingresado en el Cuerpo de Investigación y Vigilancia gracias a su aval político) se valió de un Comité de Porteros que le informaba de los vecinos que habitaban en los pisos, de su afección o desafección a la República y de las posibles llegadas de nuevos moradores.

21 El cambio de nombre de los cuerpos de Policía ha sido una constante histórica: terminada la guerra civil, Franco estableció las nuevas denominaciones de "Cuerpo General de Policia" (para los de paisano) y "Cuerpo de Policia Armada y de Tráfico" (para los uniformados). Al instaurarse la Democracia en España, los primeros pasaron a llamarse "Cuerpo Superior de Policía" y los segundos "Cuerpo de Policia Nacional", y cuando el gobierno socialista llegó al poder tras las elecciones de octubre de 1982, se produjo la unificación de ambos colectivos ( Ley 13/86 de 2 de marzo), resultando el nuevo "Cuerpo Nacional de Policía", denominación que hoy persiste. Esta idea unificadora de los organismos de Policía ya fue puesta en práctica en 1936 (por una disposición legal de 26 de diciembre de ese año) al crear el Cuerpo de Seguridad, que tenía 2 ramas la civil o de paisano y la uniformada. 
Cabos y 10.423 Guardias, cantidades que sumadas daban un total de doce mil veintiocho personas. Estos contingentes policiales (no llegaban a los 16.000) debían hacer frente a las alteraciones de la paz pública y a la investigación de los delitos en un país donde habitaban 24.012 .000 personas, de ellas 5.265.000 en las capitales de provincia ${ }^{22}$. La depuración de una parte (eso sí, pequeña) del Cuerpo de Investigación y Vigilancia se llevó a cabo por dos vías: la primera consistió en anular todos los ascensos que se habían realizado en tiempos de la dictadura primorriverista y de la monarquía por el sistema de elección de méritos. El escalafonamiento se hizo a partir de entonces por orden de rigurosa antigüedad, volviendo a situar a los miembros de Vigilancia (la medida se tomó antes de 1933, o sea, previamente al cambio de nombre) en el lugar que tenían antes del ascenso por elección de méritos. Afectó a 53 funcionarios de la Escala Técnica y a 1 vigilante conductor ${ }^{23}$. Aunque el gobierno provisional deciaró que buscaba con esta medida una mayor justicia, en realidad el Régimen republicano se ganó 54 enemigos, para los cuales los gobernantes querían lisa y llanamente castigar a los policías más recompensados por la dictadura y la monarquía. Por otro lado, los trece policías que fueron castigados con el pase a la situación de excedencia forzosa y la reducción de sus haberes a la mitad eran algunos de los más antirrepublicanos y que se habian distinguido en la desarticulación de las tramas conspirativas contra la anterior dictadura. Se les responsabilizó de haber incurrido en faltas graves de negligencia e ineptitud por los sucesos de la quema de conventos y edificios religiosos acaecidos en Madrid el día 11 de mayo de 1931. Nuevamente el gobierno provisional de izquierdas se ganó la enemiga de un grupo de funcionarios de Policía, algunos de los cuales, como el comisario Santiago Martín Báguenas, al parecer se encontraba de permiso fuera de Madrid (en Astorga). En 1935, gobernando las derechas, fueron separados del cargo 74 funcionarios del Cuerpo de Investigación y Vigilancia a causa de la falta de lealtad e íntegra devoción a los superiores. Tras los recursos interpuestos por los afectados, 67 de ellos fueron reintegrados pasado un

\footnotetext{
22 Los datos de población en nuestra nación, que están referidos al año 1932, se han obtenido del Anuario Estadistico de España (Biblioteca Nacional de Madrid). Aunque también estaban la Guardia Civil y el Cuerpo de Carabineros, el último era una policía fiscal (aduanas, contrabando, fronteras) y la primera tenía competencias en las entidades de poblacion menores, que cono. cian una corriente emigratoria progresiva hacia las ciudades más pobladas, es decir, hacia el ámbito de competencias de la Policia.

23 Boletin Oficial de la Dirección General de Seguridad de fecha 22.06.1931, consultado por el autor en el Archivo Central de la Dirección General de la Policía. Leyendo las Órdenes Gene. rales de 1923 a 1930 se repiten las felicitaciones a una serie de hombres, al parecer componentes de la Brigada de Investigación Social que perseguía las conspiraciones contra el régimen dictatorial (Santiago Martín Báguenas por ejemplo).
} 
tiempo ${ }^{24}$. Otras reformas afectaron al Gabinete de Identificación o Servicio de Identificación (reforzamiento de su papel, nombramiento como Inspector $\mathrm{Ge}$ neral del Servicio de Victoriano Mora Ruiz e implantación de una serie de instrucciones de tan buena factura que se han mantenido en sus principios básicos hasta el día de hoy) ${ }^{25}$. Asimismo, se disolvió la División de Ferrocarriles y Fronteras, cuyos cometidos pasaron a la nueva "Brigada Móvil» (el nombre ha llegados hasta nuestros dias). Asimismo, la Brigada de Investigación Criminal conoció nuevas reglas para su mejor funcionamiento ${ }^{26}$. Por último, fueron reorganizados el Servicio de Contabilidad de la Dirección General de Seguridad, el Servicio de Automovilismo, la Asesoría Jurídica y los servicios de radiotransmisión. Se atendió la protección a la infancia mediante el trasvase de impuestos de patentes por parte del Ministerio de la Gobernación hacia las deprimidas arcas del Consejo Superior y de la Junta Superior. También se hizo lo propio a favor de la protección a animales y plantas al establecer un concurso anual premiando a los miembros de Guardia Civil y Policía que más se habían destacado en la conservación de fauna y flora.

Vamos a cerrar esta exposición con un breve cuadro de los sucesos policiales ocurridos a partir del 1 de octubre de 1934. La llamada Revolución de octubre de ese año se saldó con 2 muertos y 6 heridos en el Cuerpo de Investigación y Vigilancia, 57 muertos y 20 heridos en Seguridad y Asalto y 1.051 muertos y 2.051 heridos entre paisanos y particulares ${ }^{27}$. Además del clima de violencia y de las cifras trágicas, arreciaron fuertes críticas contra la Policía y el Ejército debido a la posterior represión y a los casos de malos tratos. Las muertes y los tiroteos en las calles de toda España continuaron hasta el mismo 17 de julio (asesinatos del capitán Faraudo y del teniente Castillo, muerte del Alférez de la Guardia Civil De los Reyes, atentado contra Jiménez de Asúa que se saldó con el homicidio del agente de policía Gisbert Urreta, enfrentamientos continuos entre radicales de distinto signo, detención ilegal y muerte de Calvo Sotelo...). De poco sirvieron los esfuerzos de muchos policías por atajar la insurrección en ciernes (detención en Madrid del tradicionalista Agustín Tellería Mendizábal y aprehensión de 100 falsos uniformes de la Guardia Civil; incautación de una nota con las instrucciones que «El Director» había cursado para el alzamiento;

24 Gacetas de Madrid de los días 22.06.1935 y 11.11.1935.

25 Gaceta de Madrid del día 21.11.1934.

26 Respecto a la Brigada Móvil, se puede consultar la Gaceta de Madrid de los dias 16 y 19 de diciembre de 1933. En lo que se refiere a la Brigada o División de Investigación Criminal, las normas se publicaron en la Gaceta de Madrid del día 21 de septiembre de 1933

27 De Manuel Tuñón de Lara, Historia de España. Tomo IX. Madrid, Editorial Labor, 1983, pág. 201, se han entresacado los datos de bajas en paisanos y particulares. Los referidos a la Policia se han obtenido por elaboración propia tras la consulta de las Órdenes Generales, diarias, del Boletín Oficial de la Dirección General de Seguridad (últimos meses de 1934 y todo 1935), en el apartado de Caja de Socorros. 
arresto en Alcañiz de unos enlaces de la conspiración y captura de un documento que situaba la sublevación en el día 10 de julio; apresamiento de José Antonio Primo de Rivera y sus lugartenientes, masivas redadas de falangistas y desmantelamiento de los órganos centrales y provinciales del partido; registros del Director General de Seguridad, José Alonso Mallol, acompañado de numerosos efectivos de Madrid, Navarra y provincias vascas, en las personas y propiedades de Mola y otros complicados en Pamplona - servicio que terminó en fracaso quizá por la previa delación de Santiago Martín Báguenas-; intento de arresto de los militares sublevados en la ciudadela de Melilla, etc.). Al producirse la guerra, el Cuerpo de Investigación y Vigilancia contaba con casi 3.800 componentes y el de Seguridad y Asalto, muy incrementado durante la República, disponía de 17.660 integrantes ${ }^{28}$. Mientras el bando franquista tuvo a su favor la mayor afección del Cuerpo de Investigación y Vigilancia, los republicanos dispusieron de la mayor parte de los contingentes de Seguridad y Asalto. Unos y otros, uniformados y de paisano, franquistas y republicanos, conocerían todos los avatares y vicisitudes de una guerra: abandono del servicio, huida, ocultamiento, cárcel, refugio, embajada, marcha al frente, espionaje, depuración y muerte.

Escala técnica del cuerpo de investigación y vigilancia

\begin{tabular}{crcc}
\hline CATEG. & No INTEG. $^{\circ}$ & SUELDO $^{*}$ (ptas.) & GRATIF. (ptas.) \\
\hline COM.GR. & 1 & 15.000 & 2.500 \\
COM.JEF. & 10 & 13.000 & 1.500 \\
COM 1 & 30 & 11.500 & 1.000 \\
COM 2 & 50 & 10.500 & 1.000 \\
COM 3 & 70 & 9.500 & 1.000 \\
INSP 1 & 170 & 8.500 & 750 \\
INSP 2 & 250 & 7.000 & 750 \\
AGEN 1 & 820 & 6.000 & 500 \\
AGEN 2 & 1.090 & 4.500 & 500 \\
AGEN 3 & 950 & 3.750 & 500 \\
\hline
\end{tabular}

* Sueldo anual

Abreviaturas:

Categ.: Categorías profesionales. Integ: Integrantes.

Gratif: Gratificaciones (premiaban el servicio en festivos, nocturnos y 24 horas).

Com. Gr: Comisarios Generales.

Com. Jef.: Comisarios Jefes. Com: Comisarios.

Insp: Inspectores. Agen: Agentes.

28 La Revista "Policia" del mes de mayo de 1935 cifraba 820 agentes de $1^{\mathrm{a}}, 1.137$ de $2^{\mathrm{a}}$ y 1.090 de $3^{\mathrm{a}}$. Es decir, 187 más que en enero de 1933. De estos números falta la promoción de 1935, alrededor de los 300 aspirantes, que no acudió a la Escuela de Policía y cuyos supervivientes se reunirán, para conocerse, en plena época franquista. 
Cuerpo de seguridad y asalto

\begin{tabular}{cccc}
\hline CATEG. & No INTEG. & SUELDO (ptas.) & GRATIF. $^{*}$ (ptas.) \\
\hline CORONEL & 1 & 13.000 & 9.000 \\
TTE.COR. & 3 & 11.000 & 7.500 \\
COMTE. & 14 & 9.000 & 6.000 \\
CAPITÁN & 81 & 7.500 & 4.000 \\
TENIENTE & 231 & 5.000 & 3.250 \\
SUBOF. & 91 & 4.500 & 500 \\
SARGEN. & 310 & 4.000 & 500 \\
CABO & 874 & 3.500 & 300 \\
GUARDIA & 10.423 & 3.250 & 300 \\
\hline
\end{tabular}

* Hasta Tenientes incluidos, este concepto es la suma de indemnizaciones + gratificaciones. Los datos de ambas tablas se han extraído de la Ley de 28-12-1932 y, de manera intercalada, de la revista «Policía» 1931-1936. 